\title{
A PERCEPÇÃO DOS SERVIDORES PÚBLICOS SOBRE A SOCIALIZAÇÃO ORGANIZACIONAL: UM ESTUDO NO INSTITUTO FEDERAL DE EDUCAÇÃO, CIÊNCIA E TECNOLOGIA DO RIO GRANDE DO SUL
}

\author{
D. GENARI*, C. V. D. IBRAHIM e G. F. IBRAHIM \\ Instituto Federal de Educação, Ciência e Tecnologia do Rio Grande do Sul \\ denisegenari@hotmail.com
}

Submetido 05/10/2016 - Aceito 14/09/2017

DOI: $10.15628 /$ holos.2017.5153

\begin{abstract}
RESUMO
As instituições públicas, atualmente, têm enfrentado desafios específicos para atrair, desenvolver e reter seus profissionais. Neste contexto, pode-se destacar a importância do processo de socialização organizacional, uma vez que este possibilita que o indivíduo se familiarize com a cultura da instituição, compreenda os valores por ela praticados e adquira conhecimentos e habilidades necessárias para assumir seu papel na corporação. Diante destas afirmativas, o presente estudo tem por objetivo identificar a percepção dos servidores públicos do IFRS (Instituto Federal de Educação, Ciência e Tecnologia do Rio Grande do Sul) sobre o processo de socialização organizacional praticado pela instituição. Para tanto, realizou-se uma pesquisa de cunho quantitativo e descritivo, durante o ano de 2015, com a participação de uma amostra de 101
\end{abstract}

servidores vinculados à organização. Como principais resultados, é possível destacar a oportunidade de desenvolvimento de um programa de socialização mais abrangente, aprofundando o treinamento introdutório nas tarefas e o maior envolvimento das chefias. Além disso, identificou-se que as variáveis relacionadas ao acesso às informações, à integração às pessoas e ao conhecimento da linguagem e tradições da instituição apresentaram menores escores quando relacionadas ao processo de socialização. Em contrapartida, a qualificação dos profissionais se manifestou como um dos fatores potencialmente favorável à socialização na organização objeto deste estudo. A partir dos resultados evidenciados, espera-se contribuir para a construção de um programa de socialização organizacional mais efetivo e direcionado às necessidades do IFRS.

PALAVRAS-CHAVE: Socialização organizacional, Setor público, Gestão pública, Gestão de recursos humanos.

\section{CIVIL SERVANTS' PERCEPTION ON ORGANIZATIONAL SOCIALIZATION: A STUDY IN INSTITUTO FEDERAL DE EDUCAÇÃO, CIÊNCIA E TECNOLOGIA DO RIO GRANDE DO SUL}

\begin{abstract}
Public institutions are currently facing particular challenges to attract, develop and retain its professionals. This context highlights the importance of the organizational socialization process, since it enables one to become acquainted with the institution's culture, understand its practiced values and acquire knowledge and skills needed to assume his role in the corporation. Given these statements, the present study aims to identify the perception of IFRS (Instituto Federal de Educação, Ciência e Tecnologia do Rio Grande do Sul) civil servants on the organizational socialization process practiced by the institution. Therefore, it carries out a quantitative and descriptive natured research, in the year 2015, with 101 servants' sample bound to the organization.
\end{abstract} The main results highlight the opportunity to develop a more comprehensive socialization program, deepening tasks' introductory training and increasing managers' involvement. In addition, it finds that the variables on access to information, integration to people and knowledge of the institution's language and traditions had lower scores when related to socialization process. In contrast, the professionals' qualification is manifested as a potentially favorable factor to socialization in the organization object of this study. The obtained results are expected to contribute to developing a more effective organizational socialization program and targeted to the IFRS' needs.

KEYWORDS: Organizational socialization, Public sector, Public management, Human resources management. 


\section{INTRODUÇÃO}

A gestão de recursos humanos tem se apresentado como um fator relevante para as corporações inseridas, atualmente, em ambientes de negócios altamente competitivos, tendo em vista que as práticas decorrentes deste processo estão vinculadas à performance dos profissionais (Salanova, Agut, \& Peiró, 2005) e, consequentemente, aos resultados empresariais (Wright \& Mcmahan, 2011; Jiang, Lepak, Hu, \& Baer, 2012).

O desempenho dos indivíduos está associado aos sentimentos que estes desenvolvem em relação à organização. Os profissionais recém-contratados em uma empresa, por exemplo, apresentarão a necessidade de aceitação e buscarão internalizar os valores e as práticas da empresa (Chow, 2002). Neste sentido, dentre as práticas de gestão de recursos humanos, é possível destacar a socialização organizacional, considerando-se que esta possibilita a aquisição dos conhecimentos e o desenvolvimento das habilidades necessárias para a realização do trabalho (Chow, 2002), a atenuação das incertezas na execução das atividades (Benzinger, 2016), a demonstração clara dos papeis a serem desenvolvidos pelo novo profissional e a interação do recém-chegado com sua equipe de trabalho (Delobbe, Cooper-Thomas, \& De Hoe, 2016). Ademais, pesquisas evidenciam que a socialização está associada com aspectos comportamentais do indivíduo, tais como a intenção de permanecer na empresa, a satisfação no trabalho, a motivação, o bem-estar, o engajamento, o envolvimento e o comprometimento (Feldman, 1976; Chao, O'Leary-Kelly, Wolf, Klein, \& Gardner, 1994; Taormina, 1999; Chow, 2002; Taormina, 2004; Bigliardi; Petroni, Dormio, \& 2005, Ashforth, Sluss, \& Saks, 2007; Bauer, Bodner, Erdogan, Truxillo, \& Tucker, 2007; Tang, Liu, Oh, \& Weitz, 2014; Ellis, Bauer, Mansfield, Erdogan, Truxillo, \& Simon, 2015; Song, Chon, Ding, \& Gu, 2015).

Paralelamente, em nível organizacional, a socialização possibilita a redução da rotatividade, a alavancagem da produtividade e do desempenho corporativo e a manutenção de contratos de trabalho mais estáveis e duradouros (Chow, 2002; Song et al., 2015; Moyson, Raaphorst, Groeneveld, \& Van de Walle, 2017). Além disso, a redução dos custos com recrutamento e seleção e a melhoria da performance do indivíduo, das equipes e da corporação se apresentam como consequentes positivos do processo de socialização (Cooper-Thomas \& Anderson, 2006).

Os primeiros estudos, que trataram sobre o tema, tiveram início na década de 1960 , incentivados pela necessidade de compreensão dos aspectos que influenciam o processo de inserção do indivíduo no novo contexto corporativo, pela profissionalização da gestão de recursos humanos nas organizações e pela rotatividade, cada vez maior, de trabalhadores, entre empresas e postos de trabalho (Borges, Silva, Melo, \& Martins, 2014).

Embora, desde então, tenham ocorrido avanços nas pesquisas que abordam a socialização organizacional (Taormina, 2004; Borges \& Albuquerque, 2014), ainda percebe-se a oportunidade do aprofundamento destas, quando se trata do ambiente das organizações públicas (Oliveira et al., 2008; Hatmaker, 2015; Moyson et al., 2017). Esta constatação também se justifica ao se assinalar os diferentes objetivos do processo de recrutamento, seleção e socialização na iniciativa privada e no setor público. Enquanto, nas empresas privadas, objetiva-se maximizar os lucros, através da melhoria do desempenho e da produtividade dos indivíduos, na esfera pública buscase o aumento dos índices de eficiência, eficácia e efetividade e a melhoria na prestação de serviços à sociedade (Andrade \& Ramos, 2015). 
Além disso, verifica-se, no setor público, a oportunidade de aprimorar os processos de gestão de recursos humanos, principalmente ao se considerar os amplos investimentos realizados no processo para o recrutamento, promoção de concursos e seleção de profissionais, ao mesmo tempo em que se apresentam dificuldades em reter e obter o melhor desempenho dos servidores (Borges, Silva, Melo, \& Oliveira, 2010).

Diante das alegações apresentadas, o presente estudo tem por objetivo identificar a percepção dos servidores públicos do IFRS (Instituto Federal de Educação, Ciência e Tecnologia do Rio Grande do Sul) sobre o processo de socialização organizacional praticado pela instituição. Espera-se, a partir deste propósito, contribuir para que as ações relacionadas à socialização sejam mais efetivas e que possibilitem o alcance de resultados positivos em nível individual e organizacional.

Para o atendimento deste objetivo, este artigo está estruturado em seções, que apresentam uma revisão teórica sobre o tema socialização organizacional no setor público, os procedimentos metodológicos adotados, os principais resultados e as respectivas discussões, bem como as considerações finais e sugestões para a realização de estudos futuros.

\section{SOCIALIZAÇÃO ORGANIZACIONAL NO CONTEXTO DAS INSTITUIÇÕES PÚBLICAS}

Ao se estabelecer uma relação de trabalho, sabe-se que os profissionais e as empresas demonstram expectativas diferentes, porém complementares. De um lado, a organização espera que o empregado tenha um bom desempenho e cumpra seus deveres para com ela. De outro, o empregado espera que a organização atenda suas necessidades e cumpra com o que foi acordado (Zanelli \& Silva, 2008). Neste contexto, destaca-se o processo de socialização organizacional, que oportuniza a aprendizagem do trabalho a ser desenvolvido pelo profissional e o entendimento dos comportamentos apropriados e aceitáveis pela organização (Taormina, 2004). Com esta visão, pode-se assinalar que a socialização possibilita que o indivíduo se familiarize com a cultura da instituição (Benzinger, 2016) e compreenda, de forma mais clara, os valores por ela praticados (Delobbe, Cooper-Thomas, \& De Hoe, 2016).

O processo de socialização estabelece quais mecanismos serão adotados para influenciar o comportamento dos recém-chegados à empresa, enfocando a adoção dos valores e propósitos organizacionais, com a finalidade de adaptar os novos profissionais à realidade social da corporação (Zanelli \& Silva, 2008). Além disso, a socialização se apresenta como um fator importante, tendo em vista que possibilita que os indivíduos adquiram conhecimentos e habilidades necessárias para assumir seu papel na empresa (Van Maanen \& Schein, 1979) e realizem, adequadamente, a transição para tornarem-se membros efetivos de um grupo, organização ou sociedade (Borges et al., 2014; Tang et al., 2014). Em suma, a socialização possibilita a adequação entre o indivíduo e a organização (Moyson et al., 2017).

Ao se abordar as ações desenvolvidas durante o processo de socialização, ressaltam-se aspectos formais e informais (Benzinger, 2016). Como ações formais, a organização pode estabelecer atividades relacionadas à capacitação dos profissionais, sendo que estas promovem o aumento da satisfação com o trabalho desenvolvido, a redução da ansiedade e a intenção de permanecer na empresa. Já os aspectos informais, baseados nas interações do novo funcionário 
com seus colegas, gestores e tutores, podem representar o fator mais importante para o sucesso da socialização.

Os estudos sobre socialização organizacional podem ser compilados, conforme apresentado por Borges e Albuquerque (2014), em quatro enfoques distintos, porém complementares e integrados. O primeiro, denominado de táticas organizacionais de socialização, aborda as ações desenvolvidas pela organização e suas metas gerenciais, que objetivam facilitar o processo de socialização dos profissionais. A segunda classificação enfoca questões vinculadas à informação e conteúdos, onde são verificados os processos cognitivos do indivíduo, no que se refere ao seu papel na busca de informações, durante o processo de socialização. Neste sentido, o profissional exerce um papel proativo no seu próprio processo de socialização. O terceiro enfoque baseia-se nas tendências integradoras, no qual as ações desenvolvidas pela organização não suprimem a proatividade dos indivíduos e vice-versa.

Borges e Albuquerque (2014) também apresentam uma classificação que emerge do enfoque desenvolvimentista, alicerçada nos processos cognitivos vivenciados pelo indivíduo durante a socialização organizacional. Neste caso, o processo de socialização se daria em três estágios sequenciais (Feldman, 1976):

a) a socialização antecipatória: esta fase engloba todos os conhecimento e aprendizados desenvolvidos pelo novo profissional, antes da sua entrada na organização. Além disso, esta etapa compreende duas variáveis: o realismo, que consiste no grau de conhecimento que o indivíduo possui acerca da realidade do contexto organizacional e; a congruência, que se estabelece na compatibilidade entre os recursos disponíveis na organização e as necessidades e habilidades dos indivíduos;

b) acomodação: etapa em que o indivíduo conhece efetivamente a realidade da organização e busca tornar-se membro, com base em quatro atividades principais: aprendizagem de novas tarefas, estabelecimento de relações interpessoais com os colegas de trabalho, esclarecimento do seus papéis na organização e avaliação do seu progresso na empresa;

c) gerenciamento de papéis: esta fase está fundamentada na resolução de conflitos em duas perspectivas: conflitos entre a vida profissional e o âmbito familiar e conflitos entre os grupos de trabalho e outras esferas organizacionais, incluindo as prioridades e a forma de compartilhamento das tarefas a serem executadas.

Com base nestas perspectivas, é possível assinalar a importância da visão e da participação menos passiva do próprio profissional submetido ao processo de socialização organizacional. De acordo com Borges e Albuquerque (2014), esta perspectiva está alicerçada mais fortemente no enfoque desenvolvimentista, detalhado anteriormente.

A partir das abordagens destacadas, pode-se apontar que o processo de socialização é relevante tanto para as organizações, quanto para os profissionais, uma vez que atenua o nível de expectativas não atendidas no momento da inserção organizacional de um novo membro; favorece a performance dos indivíduos, a partir do momento em que os critérios de desempenho tornam-se mais claros e; propicia a adequação do trabalhador e a aprendizagem das normas, valores e práticas gerais da instituição (Cooper-Thomas \& Anderson, 2006). 
Esta realidade é ainda mais significativa, quando se aborda o contexto de instituições públicas, uma vez que estas enfrentam diversos desafios, tais como as questões processuais e burocráticas para a abertura de novas vagas e as dificuldades de retenção de profissionais, incluindo aqueles funcionários nos quais o poder público investiu em qualificação ou capacitação (Borges et al., 2010). Hatmaker (2015) complementa esta visão e afirma que os gestores públicos possuem o desafio de atrair profissionais competentes para que estes, posteriormente, executem de maneira adequada suas atividades e comprometam-se com a instituição na qual estão inseridos.

No setor público, a socialização apresenta um papel diferenciado em relação às ações desenvolvidas na iniciativa privada, uma vez que, neste tipo de organização, os procedimentos para recrutamento, seleção, treinamento, avaliação de desempenho e demais processos, correlatos à gestão de recursos humanos, possuem características distintas (Andrade \& Ramos, 2015). Assim, neste contexto, o processo de socialização possibilita a adequação do indivíduo para as necessidades específicas do serviço público (Moyson et al., 2017). Estas, por sua vez, estão alicerçadas em alguns deveres do servidor público, como, por exemplo: desempenhar, a tempo, as atribuições do cargo; tratar, cuidadosamente, os usuários dos serviços, aperfeiçoando o processo de comunicação e contato com o público; ter respeito à hierarquia; ser assíduo e frequente ao serviço; manter-se atualizado com as instruções, as normas de serviço e a legislação, pertinentes ao órgão onde exerce suas funções; ser probo, reto, leal e justo, demonstrando toda a integridade do seu caráter; dentre outras (Decreto n. 1171, 1994).

Ao se tratar o processo de socialização organizacional no âmbito das instituições públicas, pode-se destacar o estudo conduzido por Borges et al. (2010), a partir do desenvolvimento de uma escala que avalia sete dimensões da socialização, denominada Inventário de Socialização Organizacional (ISO). Este estudo foi baseado em um inventário previamente elaborado por Chao, Walz e Gardner (1992) e, posteriormente, adaptado à realidade brasileira por Borges, Ros e Tamayo (2001). A referida escala contempla os seguintes fatores:

a) acesso a informações: relaciona-se à possibilidade de acessar informações, saber sobre datas importantes, processos organizacionais, critérios e poder;

b) competência e proatividade: refere-se à aptidão para criar, ser eficaz, produtivo e ativo e para buscar informações;

c) integração às pessoas: dimensão alicerçada no sentimento de sentir-se aceito pelos outros, incluído na equipe, na organização e participar do processo de tomada de decisão;

d) não-integração à organização: relaciona-se à ausência do domínio da linguagem, do emprego, do conhecimento sobre os processos organizacionais e da cultura da empresa;

e) qualificação profissional: refere-se ao conhecimento e experiência profissional, domínio da linguagem profissional e de tarefas;

f) objetivos e valores organizacionais: apoia-se no conhecimento e identificação com objetivos e prioridades organizacionais e no conhecimento da história organizacional; 
g) linguagem e tradição: baseia-se no domínio da linguagem profissional e organizacional, no conhecimento das tradições e história dos colegas e na possibilidade de identificar as pessoas mais influentes.

A partir do Inventário de Socialização Organizacional, algumas investigações foram desenvolvidas em instituições públicas, no cenário nacional (Carvalho, Borges, \& Vikan, 2012; Andrade \& Ramos, 2015; Andrade, Ramos, Costa, \& Oliveira, 2016, por exemplo). No entanto, ainda percebe-se a oportunidade de expansão e aprofundamento de estudos, fato que justifica a execução da presente pesquisa no Instituto Federal do Rio Grande do Sul.

A Rede Federal de Educação Profissional, Científica e Tecnológica, vinculada ao Ministério da Educação, surgiu com o intuito de criar um novo modelo de instituição de educação profissional e tecnológica (Lei n. 11892, 2008). A Rede foi instituída em 29 de dezembro de 2008, pela Lei $n$ ㅇ 11.892, e constituída por cinco instituições, dentre as quais se destacam os Institutos Federais de Educação, Ciência e Tecnologia.

O IFRS, portanto, originou-se a partir da união de três autarquias federais, que são o Centro Federal de Educação Tecnológica de Bento Gonçalves (CEFET), a Escola Agrotécnica Federal de Sertão e a Escola Técnica Federal de Canoas (Decreto n. 6095, 2007). Após, incorporaram-se ao instituto outros dois estabelecimentos vinculados a universidades federais: a Escola Técnica Federal da Universidade Federal do Rio Grande do Sul (UFRGS) e o Colégio Técnico Industrial Prof. Mário Alquati, de Rio Grande/RS. Posteriormente, também foram federalizadas as unidades de ensino técnico nos municípios de Farroupilha, Feliz e Ibirubá.

Atualmente, o IFRS é composto por dezessete câmpus, que disponibilizam 180 opções de cursos técnicos, superiores e de pós-graduação em diferentes modalidades, atendendo cerca de quinze mil alunos. A instituição conta com um quadro funcional de, aproximadamente, 1.900 servidores, distribuídos, de forma similar, entre técnicos administrativos e docentes. Cerca de $50 \%$ dos profissionais que atuam no IFRS possuem pós-graduação em nível de mestrado ou doutorado.

O desenvolvimento deste estudo ocorreu no IFRS Câmpus Bento Gonçalves. Esta unidade é oriunda do Colégio de Viticultura e Enologia de Bento Gonçalves, fundado em 22 de outubro de 1959 e criado pela Lei no 3.646, (Lei n. 3646, 1959). Em 25 de março de 1985, a denominação alterou-se para Escola Agrotécnica Federal Presidente Juscelino Kubistchek. Em 16 de agosto de 2002, foi implantado o Centro Federal de Educação Tecnológica de Bento Gonçalves (CEFET-BG). Por fim, em 2008, foi criado o IFRS Câmpus Bento Gonçalves. A referida unidade é considerada representativa por contar com, aproximadamente, 1.400 alunos matriculados e com cerca de 230 servidores.

\section{PROCEDIMENTOS METODOLÓGICOS}

O presente estudo, de caráter descritivo, tem como objetivo principal identificar a percepção dos servidores públicos do IFRS (Instituto Federal de Educação, Ciência e Tecnologia do Rio Grande do Sul) sobre o processo de socialização organizacional praticado pela instituição. Para tanto, realizou-se uma pesquisa com a participação dos servidores públicos do IFRS Câmpus Bento Gonçalves. Durante a realização do estudo, que contou com a autorização e apoio da direção da unidade, percebeu-se o interesse dos servidores pela iniciativa. Neste sentido, não 
houve resistência por parte da instituição ou dos servidores em relação à realização do diagnóstico.

A coleta de dados ocorreu através de aplicação de um questionário, encaminhado via $e$ mail e acompanhado de uma explicação em relação ao objetivo da pesquisa, para 208 servidores. O e-mail possuía um hiperlink que direcionava os respondentes para o instrumento de pesquisa. O formulário eletrônico possuía parametrizações que objetivavam garantir a qualidade da coleta de dados (estava acessível apenas aos respondentes da pesquisa que possuíam o hiperlink, não permitia finalizar o questionário sem que todas as perguntas obrigatórias fossem preenchidas e não permitia que respostas fora de um padrão estabelecido fossem validadas). Estes cuidados auxiliaram na baixa incidência de missing values. Na época da coleta de dados (primeiro semestre de 2015), 18 servidores estavam afastados. Sendo assim, dos 190 servidores restantes, 101 responderam à pesquisa, o que corresponde a $53 \%$ da população estudada e caracteriza a amostra como não probabilística. Considerando-se que os procedimentos para a coleta de dados possibilitaram o sigilo em relação às respostas e que o e-mail encaminhado apresentava as principais informações sobre a pesquisa, julgou-se não ser necessário formalizar um termo de consentimento livre e esclarecido.

Optou-se pela aplicação do instrumento de pesquisa para todos os servidores do referido câmpus, independentemente do tempo de atuação na instituição. Esta decisão converge com a sugestão de Taormina (2004), que afirma que a mensuração da socialização organizacional objetiva avaliar a aceitação e a adaptação do profissional às diversas características da organização, ao se considerar que trata-se de um processo contínuo de aprendizagem de longo prazo. Logo, para o autor, a socialização pode ser avaliada não apenas pelos recém-chegados à organização, mas também pelos demais membros da empresa.

Em relação à elaboração do instrumento de pesquisa, seu conteúdo foi estruturado em dois blocos. O primeiro possui 30 questões originadas e adaptadas do Inventário de Socialização Organizacional, proposto por Borges et al. (2010) e apresentado, posteriormente, por Borges et al. (2014). Para este bloco, os participantes responderam se concordavam ou não com as afirmativas propostas, através de uma escala do tipo Likert, de quatro pontos, onde "1" representava "discordo totalmente" e "4" representava "concordo totalmente".

O segundo bloco do instrumento de coleta de dados apontou um conjunto de questões de informações gerais sobre os respondentes (como gênero, idade, grau de instrução, categoria profissional e tempo de trabalho na instituição). Além disso, neste bloco, procurou-se identificar as motivações que fizeram com que os profissionais buscassem o IFRS para trabalhar, as principais dificuldades que ocorreram no ingresso e se participaram anteriormente, na instituição, de algum programa de socialização organizacional. Por fim, este bloco apresentava duas questões que objetivavam verificar a percepção dos servidores em relação aos benefícios e à importância da socialização organizacional.

Destaca-se que este estudo não objetivou validar a escala de socialização organizacional proposta por Borges et al. (2010). Neste sentido, optou-se pela utilização e adaptação de algumas variáveis do Inventário de Socialização Organização. Ademais, considerando-se que, na época da coleta, dois dos autores do presente estudo faziam parte do quadro funcional da instituição, o referido instrumento foi adequado à realidade do IFRS Câmpus Bento Gonçalves, 
através de informações oriundas da observação participante e de um teste-piloto realizado com outros três servidores.

Após a coleta de dados, realizou-se a análise dos resultados, através da aplicação de técnicas relacionadas à estatística descritiva. Os principais resultados do estudo são apresentados e discutidos na próxima seção.

\section{RESULTADOS E DISCUSSÕES}

Inicialmente, através da análise descritiva, realizou-se a identificação do perfil dos respondentes da pesquisa. A partir da Figura 1, é possível evidenciar o predomínio do público feminino (56\%) na participação do estudo. A idade preponderante está entre 30 e 49 anos (70\%), com níveis representativos de instrução, ao se considerar que os $82 \%$ respondentes já finalizaram ou estão cursando pós-graduação em nível lato sensu ou stricto sensu.

Os participantes da pesquisa também foram questionados sobre suas experiências profissionais anteriores. Neste aspecto, 58\% afirmaram já ter atuado na iniciativa privada e 33\% desempenharam, no passado, atividades em outros órgãos públicos, ou seja, já vivenciaram outras situações de socialização organizacional. Em relação à atuação profissional, verificou-se que $44 \%$ dos respondentes atuam como docentes e $51 \%$ como técnicos administrativos, com tempo médio de trabalho na instituição de 6,74 anos (desvio padrão: 6,79).
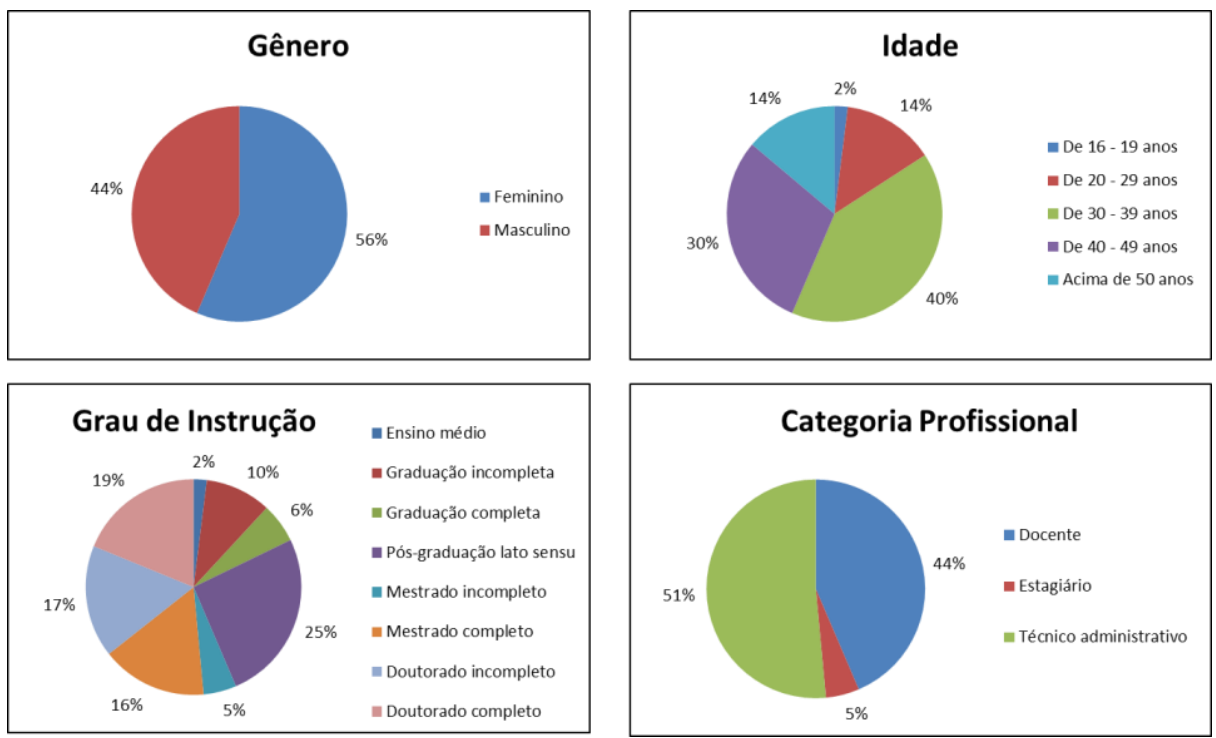

Figura 1: Dados demográficos dos respondentes da pesquisa.

Fonte: Dados compilados pelos autores, a partir dos resultados da pesquisa (2015).

Na sequência, buscou-se analisar os fatores que motivaram os profissionais participantes deste estudo a buscar uma carreira no setor público e, mais especificamente, no IFRS. Conforme descreve-se na Figura 2, a estabilidade no emprego (44\%) e a possibilidade de realização profissional (38\%) destacaram-se como os principais aspectos. No entanto, embora $43 \%$ tenham afirmado que suas expectativas foram totalmente satisfeitas neste sentido, verifica-se que o 
mesmo percentual de respondentes menciona que seus anseios foram apenas parcialmente atendidos.

Além disso, os servidores foram questionados se, ao ingressar na instituição, se depararam com uma realidade diferente da esperada. Através da realização de pesquisa prévia sobre o IFRS, $43 \%$ afirmaram que a realidade encontrada condizia com suas expectativas. Por outro lado, os demais respondentes (57\%) mencionaram desconhecer as informações principais a respeito da instituição. Este resultado torna-se interessante, ao se enfocar o aspecto desenvolvimentista da socialização organizacional, principalmente no que se refere à etapa da socialização antecipatória apresentada por Feldman (1976). A partir do resultado da pesquisa, é possível inferir que parte dos respondentes manteve uma postura pouco proativa relacionada ao conhecimento das principais informações organizacionais, antes do ingresso na instituição.
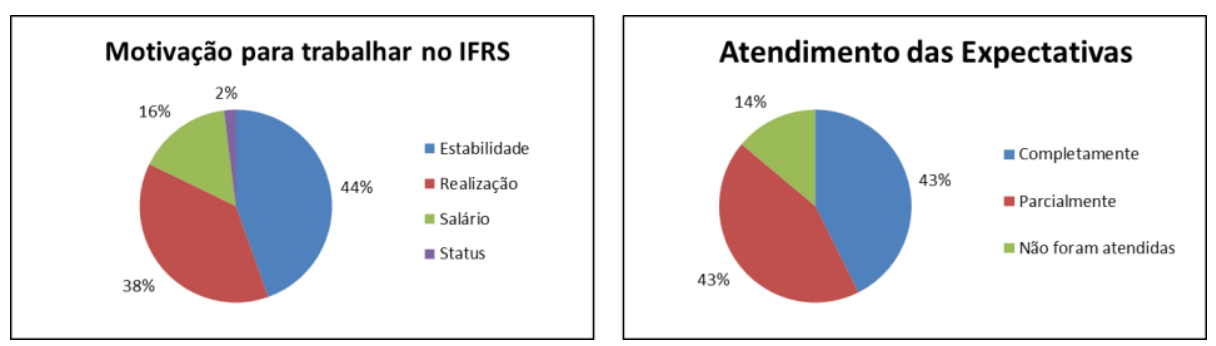

Figura 2: Motivação para trabalhar no IFRS e atendimento das expectativas. Fonte: Dados compilados pelos autores, a partir dos resultados da pesquisa (2015).

Em relação ao tema socialização organizacional, mapeou-se, conforme descrito na Figura 3 , a percepção dos respondentes em relação ao desenvolvimento deste processo no contexto do IFRS. Neste sentido, identificou-se que $72 \%$ desconhecem a existência de programas formalizados de socialização na instituição ou não participaram de tais ações. Estes resultados podem ser entendidos, considerando-se que a instituição passou a realizar ações de ambientação dos novos servidores a partir de 2014. Além disso, no mesmo ano, o IFRS elaborou e disponibilizou aos servidores um Guia de Ambientação, com as principais informações da organização, tais como estrutura e características das pró-reitorias, setores e câmpus, os veículos de comunicação adotados pela instituição, programas e projetos desenvolvidos e dicas para facilitar a integração no IFRS. Logo, considerando-se que o tempo médio de atuação no IFRS dos respondentes da pesquisa é de 6,79 anos, pode-se afirmar que muitos não participaram das referidas ações.

Em relação às principais dificuldades encontradas no momento do ingresso, percebe-se que uma parcela representativa dos participantes da pesquisa direcionou suas respostas para questões relacionadas à falta de um programa de socialização organizacional completo (46\%), à insuficiência de treinamentos para a execução das atividades (17\%) e ao pouco tempo dispendido pelas chefias, para explicar as atividades a serem desenvolvidas pelo servidor (9\%). Percebe-se, através destes resultados, a necessidade de ampliar e aprofundar as ações de capacitação dos servidores, inclusive no que se refere ao papel da gestão na socialização dos profissionais. Destaca-se, neste contexto, a importância do comportamento e da visão da liderança em relação ao novo servidor, principalmente ao se considerar que a gestão é um elemento-chave para que a socialização organizacional seja bem-sucedida (Taormina, 2008). 


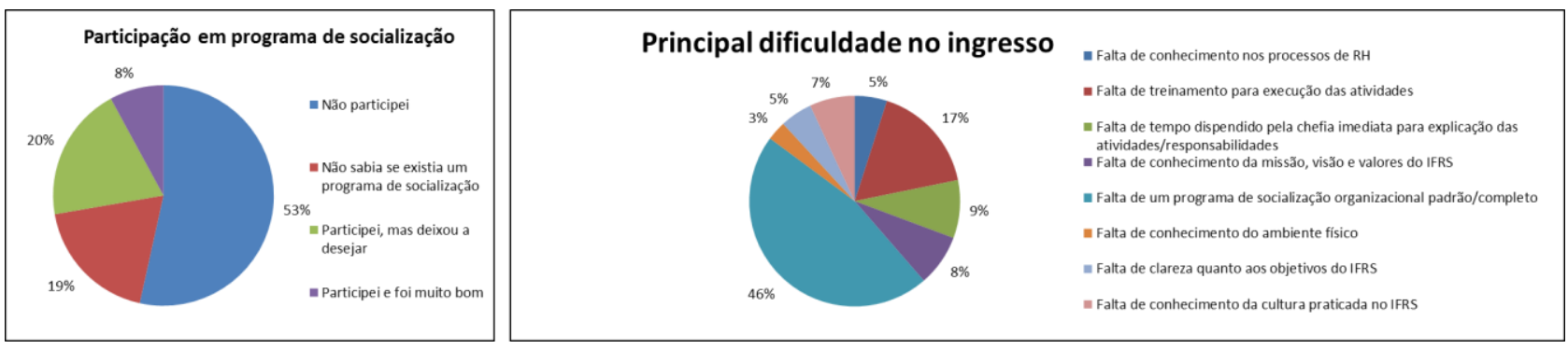

Figura 3: Participação em programa de socialização e principais dificuldades no momento do ingresso. Fonte: Dados compilados pelos autores, a partir dos resultados da pesquisa (2015).

Por outro lado, os participantes da pesquisa foram questionados a respeito dos benefícios visualizados e decorrentes das ações de socialização organizacional. De acordo com os resultados evidenciados na Figura 4, percebe-se que a vertente relacionada ao acesso às informações apresentou-se como a mais representativa na visão dos servidores pesquisados. Neste sentido, 29\% apontaram como principal benefício das ações de socialização, a melhoria da comunicação, reduzindo o tempo para obtenção de informações. Além disso, $43 \%$ dos respondentes assinalaram que o conhecimento da linguagem e dos processos organizacionais se configura como um aspecto importante da socialização. Este resultado é corroborado por Borges et al. (2014), no momento em que os autores afirmam que, atualmente, os servidores públicos têm a oportunidade de acessar informações de maneira ampliada. No entanto, ainda existe uma dificuldade em selecionar àquelas disponíveis, bem como de identificar e conhecer as fontes de informação mais adequadas.

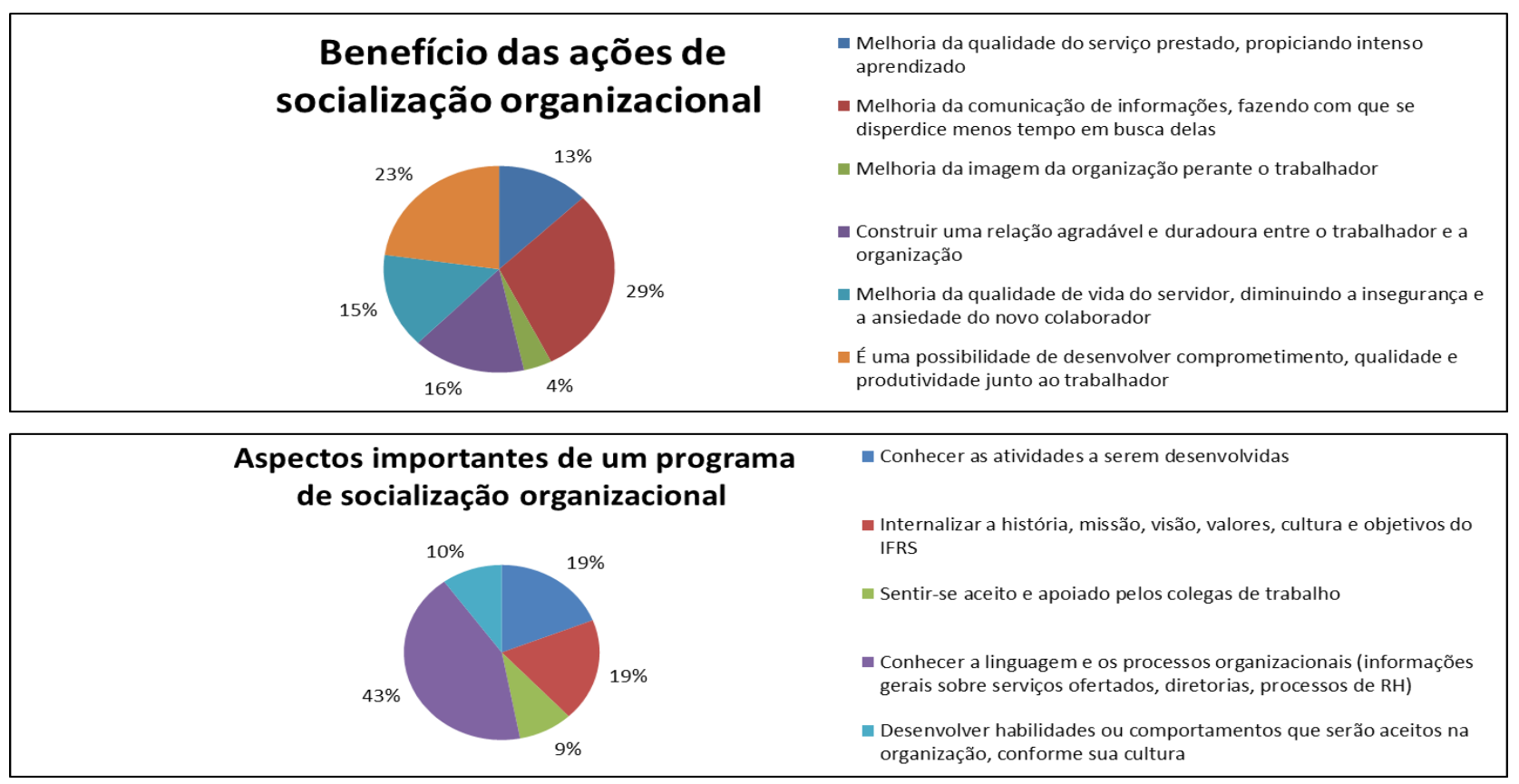

Figura 4: Benefícios e aspectos importantes de um programa de socialização organizacional. Fonte: Dados compilados pelos autores, a partir dos resultados da pesquisa (2015). 
Por fim, a partir da seleção de algumas variáveis disponíveis no Inventário de Socialização Organizacional (Borges et al., 2010; Borges et al., 2014), analisou-se as respostas dos participantes da pesquisa, sobre suas percepções em relação à socialização no IFRS Câmpus Bento Gonçalves. Os resultados estão apresentados na Tabela 1 e ordenados de acordo com a média calculada para cada variável.

Tabela 1: Variáveis analisadas sobre a socialização organizacional.

\begin{tabular}{|c|c|c|}
\hline Variável & Média & Desvio padrão \\
\hline $\begin{array}{l}\text { Ter acesso às informações sobre todos os serviços oferecidos pela } \\
\text { organização. }\end{array}$ & 2,46 & 0,81 \\
\hline Confiar na maioria dos colegas de trabalho. & 2,55 & 0,70 \\
\hline $\begin{array}{l}\text { Dominar as siglas, abreviações e termos utilizados pelos membros da } \\
\text { organização para denominar setores, processos ou tecnologias de trabalho. }\end{array}$ & 2,65 & 0,77 \\
\hline Conhecer a história anterior do setor de trabalho. & 2,69 & 0,72 \\
\hline $\begin{array}{l}\text { Ter uma boa compreensão das normas, intenções e formas de procedimento } \\
\text { da organização. }\end{array}$ & 2,76 & 0,69 \\
\hline $\begin{array}{l}\text { Conhecer as datas que são significativas e comemoradas tradicionalmente } \\
\text { pela organização. }\end{array}$ & 2,77 & 0,63 \\
\hline Conhecer as tradições enraizadas da organização. & 2,77 & 0,61 \\
\hline Estar sintonizado às prioridades desta organização. & 2,77 & 0,65 \\
\hline Participar das decisões do setor de trabalho. & 2,79 & 0,78 \\
\hline Ser familiarizado com a história da organização. & 2,85 & 0,64 \\
\hline Estar familiarizado com os costumes e hábitos da organização. & 2,88 & 0,68 \\
\hline Saber quem são as pessoas mais influentes nas decisões da organização. & 2,90 & 0,77 \\
\hline Apoiar os objetivos que são estabelecidos pela organização. & 2,91 & 0,55 \\
\hline Sentir-se integrado à organização. & 2,91 & 0,66 \\
\hline $\begin{array}{l}\text { Ter a possibilidade de identificar os trâmites burocráticos necessários ao } \\
\text { desempenho das minhas tarefas. }\end{array}$ & 2,92 & 0,54 \\
\hline Ser conhecido por muitas pessoas na organização. & 2,95 & 0,68 \\
\hline Ter objetivos que coincidem com os objetivos desta organização. & 2,96 & 0,51 \\
\hline $\begin{array}{l}\text { Ser frequentemente incluído nos grupos de amizade das pessoas da } \\
\text { organização. }\end{array}$ & 2,99 & 0,67 \\
\hline Saber quais são os objetivos da organização. & 3,03 & 0,61 \\
\hline Saber a quem procurar quando precisar de informações. & 3,04 & 0,60 \\
\hline Identifica-se como um membro da equipe. & 3,07 & 0,71 \\
\hline $\begin{array}{l}\text { Tomar conhecimento das tarefas por iniciativa própria, observando e } \\
\text { fazendo. }\end{array}$ & 3,11 & 0,56 \\
\hline Sentir-se aceito e acolhido pelos colegas do meu setor de trabalho. & 3,13 & 0,64 \\
\hline Estar preparado para atingir um melhor desempenho no emprego. & 3,21 & 0,75 \\
\hline Considerar colega de trabalho como amigo. & 3,25 & 0,78 \\
\hline Compreender o específico significado das palavras e termos da profissão. & 3,28 & 0,59 \\
\hline Ter domínio em relação às tarefas requeridas pelo emprego. & 3,30 & 0,61 \\
\hline Experiência anterior ajudar na adaptação ao cargo. & 3,32 & 0,68 \\
\hline Conhecimentos profissionais ajudaram na adaptação ao cargo. & 3,35 & 0,65 \\
\hline Dominar as palavras específicas usadas no trabalho. & 3,40 & 0,65 \\
\hline
\end{tabular}

Fonte: Dados compilados pelos autores, a partir dos resultados da pesquisa (2015). 
Inicialmente, é possível destacar três dimensões de variáveis que se apresentaram com as menores médias. Neste sentido, aponta-se as questões relacionados ao acesso às informações, à integração às pessoas e à linguagem e tradição da organização. Em relação ao acesso às informações, percebe-se que, segundo os participantes da pesquisa, existe certa dificuldade em acessar as informações sobre os serviços oferecidos pela organização. Além disso, evidenciou-se que não há um conhecimento pleno sobre as datas significativas e comemoradas tradicionalmente pela instituição. Estes resultados convergem com os dados apresentados na Figura 4, onde os servidores apontaram a gestão das informações e o conhecimento sobre os processos e serviços ofertados pela organização como benefícios potenciais da socialização organizacional.

A confiança nos colegas de trabalho, a participação das decisões do setor e a familiaridade com os costumes e hábitos da organização também se apresentaram como variáveis com as menores médias. De acordo com o estudo de Borges et al. (2010), estas variáveis estão relacionadas ao fator denominado integração às pessoas. Esta dimensão aborda a percepção do indivíduo em relação à sua integração com os demais membros da organização, no sentido de sentir-se incluído, aceito e apoiado pelos colegas e seus respectivos grupos. Além disso, este fator engloba a facilidade de acesso aos demais sujeitos que pertencem à instituição. Considerando-se os resultados aqui identificados, percebe-se a oportunidade de aprimorar a integração do indivíduo com os membros da organização, considerando-se que esta questão se apresenta como um fator importante na socialização organizacional.

Algumas variáveis vinculadas ao fator, denominado por Borges et al. (2010) como "linguagem e tradição", também merecem atenção. Neste sentido, identificou-se que questões relacionadas ao domínio de siglas, abreviações e termos utilizados pelos membros da organização para denominar setores, processos ou tecnologias de trabalho, com o conhecimento da história anterior do setor de trabalho, com a compreensão das tradições enraizadas da organização, com a familiaridade com a história de instituição e com a clareza em relação a quem são as pessoas mais influentes nas decisões da organização, apresentaram algumas das menores médias.

A partir deste resultado, é possível apontar a oportunidade de abordar de maneira mais efetiva a divulgação, para os servidores, dos principais termos específicos que sejam adotados pela instituição, bem como destacar os principais fatores históricos e culturais da organização. Além disso, percebe-se a necessidade de esclarecer a estrutura do processo de tomada de decisões organizacionais e as respectivas pessoas envolvidas.

Outro resultado que pode ser salientado está relacionado às variáveis pertinentes à qualificação profissional dos respondentes da pesquisa. Apresentaram-se, com algumas das maiores médias, as questões vinculadas à compreensão do significado específico das palavras e termos da profissão, à experiência anterior auxiliar na adaptação ao cargo atual e aos conhecimentos profissionais ajudarem na adaptação ao cargo. Conforme apontado por Borges et al. (2010), a qualificação profissional está embasada na percepção do indivíduo em relação à sua preparação prévia para exercer o cargo e atender às expectativas da organização. Esta preparação, por sua vez, possui relação com os conhecimentos e experiência anteriores do profissional. Este resultado identificado pode ser explicado com base no próprio perfil dos respondentes, sendo que $82 \%$ estão cursando ou já concluíram formação em nível de pós- 
graduação e possui experiências anteriores na iniciativa privada ou em instituições públicas (91\%).

\section{CONSIDERAÇÕES FINAIS}

O processo de socialização é importante, tanto para as organizações quanto para o profissional envolvido, uma vez que prepara os indivíduos para adequarem-se à nova realidade empresarial, favorecendo o entendimento para a execução das tarefas, o maior comprometimento perante a organização, o acesso às informações da corporação, bem como a ampliação da confiança junto aos colegas de trabalho e gestores. A partir destas premissas, o objetivo do presente estudo foi verificar a percepção dos colaboradores do IFRS sobre o processo de socialização organizacional praticado.

Diante disso, considera-se importante apontar algumas ações que podem ser aplicadas para melhorar o processo de socialização organizacional existente na instituição, haja vista os principais resultados alcançados com a pesquisa. Inicialmente, verificando-se que mais da metade dos respondentes afirmaram desconhecer a existência de programas formais de socialização organizacional ou não tiveram a oportunidade de participar das novas ações de ambientação, promovidas pela instituição desde 2014, a divulgação, ampliação e aplicação de um programa de socialização completo faz-se necessário.

Com o objetivo de contextualizar e desenvolver o novo servidor junto às atividades a serem executadas, o programa poderia dar ênfase às tarefas, através do envolvimento e treinamento realizado pelas chefias do recém-chegado, a fim de que este seja capaz de executálas de maneira eficiente e eficaz. Também considera-se relevante apontar a possibilidade de implementação de um programa de tutoria, sendo que o tutor poderia realizar o acompanhamento do desenvolvimento inicial das atividades do novo servidor, auxiliando-o com recursos, informações, apoio e ferramentas necessárias para que o profissional tenha condições de exercer suas atribuições com segurança e responsabilidade.

A partir das ações de tutoria, aponta-se a oportunidade para que a gestão divulgue de forma mais clara e sistematizada as informações importantes sobre a instituição. Além disso, preconiza-se que a tutoria poderá favorecer a integração do novo servidor com a organização, fato que promoverá a maior familiaridade deste com os costumes e hábitos da instituição, a melhoria das relações e o desenvolvimento de laços mais fortes com os colegas de trabalho.

Outra necessidade que merece destaque está vinculada ao desenvolvimento de canais de comunicação institucional mais integrados e direcionados ao novo servidor. Neste sentido, a implementação destas ferramentas poderá favorecer o entendimento sobre os termos adotados pela instituição, a padronização das fontes de dados e a maior autonomia do profissional na obtenção de informações e na tomada de decisões.

Considerando-se que o presente estudo foi desenvolvido em uma unidade específica do IFRS, não se pretende esgotar a discussão sobre os resultados encontrados. Sendo assim, sugerese a aplicação do Inventário de Socialização Organizacional, de forma integral, em todos os câmpus da instituição. A partir desta ação, será possível avaliar as dimensões mais representativas da socialização, conforme proposto por Borges et al. (2010), bem como verificar as diferenças significativas de acordo com o perfil dos respondentes e as respectivas unidades da 
instituição. Com base nesta proposta, torna-se viável elaborar ações direcionadas, que promoverão um processo mais bem-sucedido de socialização organizacional.

Devido à pluralidade de abordagens vinculadas à socialização, considera-se relevante elencar outras sugestões para estudos futuros. Estas proposições poderão complementar ou, até mesmo, auxiliar no avanço do entendimento da dinâmica que envolve este tema. Além disso, percebe-se a necessidade de avançar na realização de estudos sobre a gestão de recursos humanos no setor público. Assim, sugere-se desenvolver novos estudos que explorem, no contexto destas instituições, a relação existente entre a socialização e alguns possíveis elementos consequentes deste processo, tais como a satisfação com o trabalho, o comprometimento e a intenção de rotatividade.

\section{AGRADECIMENTOS}

Este trabalho está sendo apoiado pelas seguintes instituições: Faculdade Cenecista de Bento Gonçalves (CNEC Bento), Instituto Federal de Educação, Ciência e Tecnologia do Rio Grande do Sul (IFRS), Universidade de Caxias do Sul (UCS) e Coordenação de Aperfeiçoamento do Pessoal de Nível Superior (CAPES).

\section{REFERÊNCIAS}

Andrade, D. C. T., \& Ramos, H. R. (2015). A comparação entre grupos ocupacionais e lotação setorial/departamental de uma IFES sob a ótica da socialização organizacional. Revista Economia \& Gestão, 15(39), 104-125.

Andrade, D. C. T., Ramos, H. R., Costa, D. M. D., \& Oliveira, D. R. (2016). A socialização organizacional dos servidores de uma IFES: em tempos de REUNI. Revista da Universidade Vale do Rio Verde, v. 14, n. 1, 14(1), 670-691.

Ashforth, B. E., Sluss, D. M., \& Saks, A. M. (2007). Socialization tactics, proactive behavior, and newcomer learning: Integrating socialization models. Journal of Vocational Behavior, 70(3), 447-462.

Bauer, T. N., Bodner, T., Erdogan, B., Truxillo, D. M., \& Tucker, J. S. (2007). Newcomer adjustment during organizational socialization: a meta-analytic review of antecedents, outcomes, and methods. Journal of Applied Psychology, 92(3), 707-721.

Benzinger, D. (2016). Organizational socialization tactics and newcomer information seeking in the contingent workforce. Personnel Review, 45(4), 743-763.

Bigliardi, B., Petroni, A., \& Dormio, A. I. (2005). Organizational socialization, career aspirations and turnover intentions among design engineers. Leadership \& Organization Development Journal, 26(6), 424-441.

Borges, L. O., Ros, M., \& Tamayo, A. (2001). Socialización organizacional: tácticas y autopercepción. Revista de Psicología del Trabajo y de las Organizaciones, 17(2), 173-196.

Borges, L. O., Silva, F. H. V. C., Melo, S. L., \& Oliveira, A. S. (2010). Reconstrução e validação de um inventário de socialização organizacional. Revista de Administração Mackenzie, 11(4), 4-37. 
Borges, L. O., Silva, F. H. V. C., Melo, S. L., \& Martins, A. S. O. (2014). Socialização Organizacional. In Siqueira, M. M. M. Novas medidas do comportamento organizacional: ferramentas de diagnóstico e de gestão. (268-279). Porto Alegre: Artmed.

Borges, L. O., \& Albuquerque, F. J. B. (2014). Socialização Organizacional. In Zanelli, J. C., BorgesAndrade, J. E., Bastos, A. V. B. Psicologia, Organizações e Trabalho no Brasil. 2. ed. (351-384). Porto Alegre: Artmed.

Carvalho, V., Borges, L. O., \& Vikan, A. (2012). Socialização organizacional: estudo comparativo entre servidores públicos brasileiros e noruegueses. Revista Eletrônica de Administração, 18(2), 339-371.

Chao, G. T., Walz, P., \& Gardner, P. D. (1992). Formal and informal mentorships: a comparison on mentoring functions and contrast with nonmentored counterparts. Personnel Psychology, 45(3), 619-636.

Chao, G. T., O'Leary-Kelly, A. M., Wolf, S., Klein, H. J., \& Gardner, P. D. (1994). Organizational socialization: its content and consequences. Journal of Applied Psychology, 79(5), 730-743.

Chow, I. H. (2002). Organizational socialization and career success of Asian managers. International Journal of Human Resource Management, 13(4), 720-737.

Cooper-Thomas, H. D., \& Anderson, N. (2006). Organizational socialization: a new theoretical model and recommendations for future research and HRM practices in organizations. Journal of Managerial Psychology, 21(5), 492-516.

Decreto n. 1171, de 22 de junho de 1994 (1994). Aprova o Código de Ética Profissional do Servidor Público Civil do Poder Executivo Federal. Brasília, DF: Presidência da República, Casa Civil.

Decreto n. 6095, de 24 de abril de 2007 (2007). Estabelece diretrizes para o processo de integração de Instituições Federais de Educação Tecnológica, para fins de constituição dos Institutos Federais de Educação, Ciência e Tecnologia - IFET, no âmbito da Rede Federal de Educação Tecnológica. Brasília, DF: Presidência da República, Casa Civil.

Delobbe, N., Cooper-Thomas, H. D., \& De Hoe, R. (2016). A new look at the psychological contract during organizational socialization: the role of newcomers' obligations at entry. Journal of Organizational Behavior, 37(6), 845-867.

Ellis, A. M., Bauer, T. N., Mansfield, L. R., Erdogan, B., Truxillo, D. M., \& Simon, L. S. (2015). Navigating uncharted waters: Newcomer socialization through the lens of stress theory. Journal of Management, 41(1), 203-235.

Feldman, D. C. (1976). A contingency theory of socialization. Administrative Science Quarterly, 21(3), 433-452.

Hatmaker, D. M. (2015). Bringing Networks In: a model of organizational socialization in the public sector. Public Management Review, 17(8), 1146-1164.

Jiang, K., Lepak, D. P., Hu, J., \& Baer, J. C. (2012). How does human resource management influence organizational outcomes? A meta-analytic investigation of mediating mechanisms. Academy of Management Journal, 55(6), 1264-1294.

Lei n. 3646, de 22 de outubro de 1959 (1959). Cria a Escola de Viticultura e Enologia de Bento Gonçalves, no Estado do Rio Grande do Sul, e dá outras providências. Rio de Janeiro, RJ: Congresso Nacional. 
Lei n. 11892, de 29 de dezembro de 2008 (2008). Institui a Rede Federal de Educação Profissional, Científica e Tecnológica, cria os Institutos Federais de Educação, Ciência e Tecnologia, e dá outras providências. Brasília, DF: Presidência da República, Casa Civil.

Moyson, S., Raaphorst, N., Groeneveld, S., \& Van de Walle, S. (2017). Organizational socialization in public administration research: A systematic review and directions for future research. The American Review of Public Administration, 0(0), 1-18.

Oliveira, S. D. C., Lino, M. A. B., Borges, L. O., Carvalho, V. D., Melo, S. L., Silva, A. K. L. et al. (2008). A socialização organizacional dos servidores da UFRN, segundo grupo ocupacional e tempo de serviço. Revista Psicologia: Organizações e Trabalho, 8(1), 118-141.

Salanova, M., Agut, S., \& Peiró, J. M. (2005). Linking organizational resources and work engagement to employee performance and customer loyalty: the mediation of service climate. Journal of applied Psychology, 90(6), 1217-1227.

Song, Z., Chon, K., Ding, G., \& Gu, C. (2015). Impact of organizational socialization tactics on newcomer job satisfaction and engagement: Core self-evaluations as moderators. International Journal of Hospitality Management, 46, 180-189.

Tang, C., Liu, Y., Oh, H., \& Weitz, B. (2014). Socialization tactics of new retail employees: A pathway to organizational commitment. Journal of Retailing, 90(1), 62-73.

Taormina, R. J. (1999). Predicting employee commitment and satisfaction: The relative effects of socialization and demographics. International Journal of Human Resource Management, 10(6), 1060-1076.

Taormina, R. J. (2004). Convergent validation of two measures of organizational socialization. The International Journal of Human Resource Management, 15(1), 76-94.

Taormina, R. J. (2008). Interrelating leadership behaviors, organizational socialization, and organizational culture. Leadership \& Organization Development Journal, 29(1), 85-102.

Van Maanen, J., \& Schein, E.H. (1979). Toward a theory of organizational socialization, Research in Organizational Behaviour, 1(JAI Press, Greenwich, CT), 209-264.

Wright, P. M., \& McMahan, G. C. (2011). Exploring human capital: putting 'human'back into strategic human resource management. Human Resource Management Journal, 21(2), 93104.

Zanelli, J. C., \& Silva, N. (2008). Interação humana e gestão: a construção psicossocial das organizações de trabalho. São Paulo: Casa do Psicólogo. 